Preprint de "An undominated Nash equilibrium for voting by committees with exit," de Dolors Berga, Gustavo Bergantiños, Jordi Massó i Alejandro Neme. Mathematical Social Sciences 54, 152-175 (2007). Lliurat a Elsevier el març de 2007. 


\title{
An Undominated Nash Equilibrium for Voting by Committees with Exit
}

\author{
Dolors Berga $^{* \dagger}$, Gustavo Bergantiños ${ }^{\ddagger}$, Jordi Massó ${ }^{\S}$, and Alejandro \\ Neme
}

March 2007

\begin{abstract}
We consider the problem of a society whose members choose, with a voting by committees, a subset of new members from a given set of candidates. After knowing the elected candidates, former members may decide either stay or exit the society. We analyze the voting behavior of members who take into account the effect of their votes not only on the elected candidates, but also on the final composition of the society. For additive and monotonic preferences with dichotomous bads we construct a strategy profile that is an undominated pure strategy Nash equilibrium of the induced voting game.
\end{abstract}

Keywords: Voting; Committees; Undominated Nash Equilibrium

JEL classification: D71

${ }^{*}$ Corresponding author: Departament d'Economia. Universitat de Girona. Campus de Montilivi. 17071 Girona. Spain. Telf.: +34972418738. Fax: +34972418032.

E-mail address: dolors.berga@udg.es

${ }^{\dagger}$ Departament d'Economia, Campus de Montilivi, Universitat de Girona, 17071, Girona, Spain

${ }^{\ddagger}$ Research Group in Economic Analysis, Universidade de Vigo, 36200, Vigo (Pontevedra), Spain

$\S$ Departament d'Economia i d'Història Econòmica and CODE, Universitat Autònoma de Barcelona, Bellaterra (Barcelona), 08193, Spain

『Instituto de Matemática Aplicada de San Luis, Universidad Nacional de San Luis and CONICET, Ejército de los Andes 950, San Luis, 5700, Argentina 


\section{Introduction}

Societies use voting rules to make decisions. The elections of representatives in democratic societies, the public positions taken up by political parties on different issues, or the admission of new members in a society are some examples of this. For this last example, Barberà, Sonnenschein, and Zhou (1991) consider the problem where a finite set of members who originally make up a society has to decide which candidates, to be chosen from a given set, will be elected to become new members of the society. They assume that former members of the society cannot leave it as a result of its change in composition. But often, the entrance of new members trigger the exit of former ones. For the static setting where members cannot leave the society, they characterize voting by committees as the class of strategy-proof and onto social choice functions whenever members' preferences over subsets of candidates are either separable or additively representable. However, strategy-proofness becomes too strong whenever the mentioned evolution of the society is explicitly considered. The aim of this paper is to study the strategic behavior of members by means of the analysis of undominated pure strategy Nash equilibria in a complete information setting where all members' preferences are common knowledge. ${ }^{1}$

Three lines of research have already focused on the analysis of strategic equilibria under complete information. A first one considers a society that, during a fixed and commonly known number of periods, may admit in each period a subset of new members. Within this dynamic setup, an interesting issue arises: voters, at earlier stages, vote not only according to whether or not they like a candidate but also according to their tastes concerning future candidates. Barberà, Maschler, and Shalev (2001) study the particular case where members have dichotomous preferences (candidates are either friends or enemies) and the voting rule used by the society is quota one (it is sufficient to receive one vote to be elected). They identify and study (subgame perfect and trembling-hand perfect) equilibria where members exhibit, due to the dynamics of the game, complex strategic voting behavior. Granot, Maschler, and Shalev (2002) study a similar model with expulsion; current members of the society have to decide each period whether to admit by unanimity new members into the society and whether to expel current members by others' unanimity. They study equilibria for different protocols which depend on whether the expulsion decision has

\footnotetext{
${ }^{1} \mathrm{~A}$ more difficult line of research would consist of considering incomplete information and concentrating on the analysis of Bayesian equilibria, for example. But this is outside the scope of this paper.
} 
to be taken each period either simultaneously with, before, or after the admission decision.

In a second line of research, a set of voters and a set of candidates (which may overlap) must select a representative candidate (or a subset of them). The key issue this literature addresses is the incentives of candidates, given a particular voting rule (how voters choose a candidate or a subset of candidates), to enter or exit the election in order to strategically affect the outcome of the rule. By imposing some independence conditions and an "internal stability" condition (the losing candidates must not have an incentive to drop out of the election) they prove that the class of voting rules immune to this strategic manipulation is only composed of dictatorial rules. $^{2}$

In this paper we contribute on a third line of research by considering explicitly the possibility that, in the Barberà, Sonnenschein, and Zhou's (1991) setup members who originally conform a society have the option to leave it voluntarily. In Berga, Bergantiños, Massó, and Neme (2004) we showed that the unique social choice function that is still strategy-proof, stable, and satisfies founders' sovereignty on the set of candidates is the voting by committees that requires unanimity for the entrance of each candidate. ${ }^{3}$ The dynamic aspect of this decision is hidden in the general formulation of the mechanism as a social choice function. In Berga, Bergantiños, Massó, and Neme (2006) we concentrate on particular mechanisms where the final society, consisting of the subset of elected candidates and the subset of members that decide to stay in the society, is the outcome of a two-stage game; hence, formulating explicitly the dynamics of the decision. First, members choose a subset of candidates by a given voting procedure. Second, and after knowing the set of elected candidates $X$, members of the society decide whether to stay or exit the society. This model is strategically rich because a member, when evaluating the consequences of a vote for a particular candidate $x$, has to take into account (not only whether or not he likes $x$ but also) two simultaneous effects (and their ramifications) of $x$ being chosen.

\footnotetext{
${ }^{2}$ See Dutta, Jackson, and Le Breton (2001) for single-valued voting rules, and Ehlers and Weymark (2003), Eraslan and McLennan (2004), and Rodríguez-Álvarez (2006) for multi-valued voting rules.

${ }^{3}$ Stability requires the exit to be voluntary; that is, for any preference profile the social choice function has the property that all members belonging to the final society want to stay (internal stability) and all members who do not belong to the final society do not want to belong (external stability). Founders' sovereignty on the set of candidates requires that candidates that are good for all members have to be admitted to the society and candidates that are bad for all members cannot be admitted.
} 
First, the choice of $x$ might be used by member $i$ to get rid of member $j$ if $i$ does not like $j$ and $j$ does not like candidate $x$ (similar and even more involved consequences of $x$ being chosen may arise as well; for instance, $i$ might like $j$ but not $j^{\prime}$ who belongs to the society just because $j$ is a member of it, but $j^{\prime}$ would leave it as soon as $j$ exits it; i.e., $i$ votes for $x$ to get rid of $j^{\prime}$ by bringing about the exit of $j$ ). Second, support of candidate $x$ might be used by member $i$ to keep member $j^{\prime \prime}$, who is ready to leave the society whenever candidate $y$ is chosen (the chosen one if $i$ does not vote for $x$ ), because $j^{\prime \prime}$ 's membership is critical for $i$ 's continued presence in the society (and further obvious effects). In this setting, we exhibited an example without any subgame perfect Nash equilibria in pure strategies and another one in which in all subgame perfect Nash equilibria in pure strategies at least one player uses a dominated strategy.

For societies whose members perceive the membership of all other members as being desirable (monotonic preferences) we were able to identify, for each subset of elected candidates $X$, a reasonable and meaningful subset of members that leave the society $(E A(X)$, the exit set after $X$ is chosen $)$. This set has desirable properties and it is identified by means of a recursive process that mimics the iterative elimination of dominated strategies.

Here, we add more structure to the problem. First, we assume that the society uses voting by committees to elect its new members. Second, we suppose that member's preferences are not only additive in the sense of Barberà, Sonnenschein, and Zhou (1991) but also have dichotomous bads. A candidate $x$ is bad for member $i$ if adding $x$ to any society makes the society worse for $i$. An additive preference of member $i$ has dichotomous bads if each bad candidate (if any) is either extremely bad (his entrance makes the society to be, in any circumstance, undesirable for member $i$ ) or mildly bad (his entrance does not affect his exit decision). Our main result here is that, under this preference domain, the game induced by a voting by committees without vetoers has at least an undominated Nash equilibrium in pure strategies. Note that if the election of candidates was done using voting by quota, Proposition 4 in Berga, Bergantiños, Massó, and Neme (2006) would assure us the existence of Nash equilibria in pure strategies. ${ }^{4}$ Although we consider the more general framework of voting by committees, for reasons of tractability we restrict ourselves to the analysis of pure strategy Nash equilibria.

Observe that in general voting by committees have, even without exit, a large

\footnotetext{
${ }^{4}$ The unique case where we can not guarantee the existence of Nash equilibria in pure strategies is when voting by committees is voting by quota 1 and exit is simultaneous.
} 
set of pure strategy Nash equilibria, many of them without much predictive power. Take an arbitrary subset of candidates and assume all members vote for, and only for this subset (this has been known in the literature as "common voting"). As long as the voting by committees does not have vetoers nor decisive voters this arbitrary voting strategy is a Nash equilibrium since the outcome is invariant with respect to any unilateral deviation. However, in this strategy profile many voters may be using a dominated strategy.

In this paper we look for a reasonable undominated pure strategy Nash equilibrium and we obtain it by the following recursive construction. At each stage, each member votes for his best subset of candidates given the set that has already been admitted in the previous stages and taking into account the exit it will induce. Given their votes (for the stage) the set of candidates joining the society (at this stage) is chosen according to the voting by committees. The process ends at the stage where no additional candidate would be admitted. From the overall set of candidates that each member has voted for along this process, we construct a strategy profile (a simultaneous vote for each member) that is an undominated Nash equilibrium in pure strategies of the induced game with exit.

Before finishing this introduction we want to point out that our model is not limited to the interpretation given so far; i.e., the choice of the composition of the final society. It can be also used to analyze the problem where a society has to define its formal and public positions on a set of issues. One can think of political parties or religious communities deciding on different issues like abortion, death penalty, health reform, and so on.

The paper is organized as follows. In Section 2 we introduce our basic framework. In Section 3 we define the game induced by a voting by committees and the exit set after a subset of candidates has been elected. In Section 4 we describe the domain of preferences with dichotomous bads and we obtain some properties of the exit set under this preference domain. In Section 5 we construct an undominated Nash equilibrium in pure strategies and state our main result (Theorem 1). Four Appendices at the end of the paper contain the proofs of three propositions and the theorem omitted in the text. 


\section{Preliminaries}

Let $N=\{1, \ldots, n\}$ be the set of members of a society who must first choose a subset of new members among the finite set of candidates $K$. Then, knowing the elected candidates, each member decides to stay or to leave the society. Members in $N$ have preferences over $2^{K} \times 2^{N}$, the set of all possible final societies. Namely, a final society is a pair $[X, S] \in 2^{K} \times 2^{N}$ where $X$ is the set of elected candidates and $S$ is the set of members who stay in the society given that $X$ has been elected. ${ }^{5}$ To simplify notation we will often denote a final society $[X, S]$ by $X \cup S$.

The preferences of member $i \in N$ over $2^{K} \times 2^{N}$, denoted by $R_{i}$, is a complete, reflexive, and transitive binary relation. As usual, let $P_{i}$ and $I_{i}$ denote the strict and indifference preference relations induced by $R_{i}$, respectively. We suppose that each member's preferences $R_{i}$ satisfies the following five conditions: ${ }^{6}$

(C1) Strictness: For all $X, X^{\prime} \subset K$ and $S, S^{\prime} \subset N$ such that $[X, S] \neq\left[X^{\prime}, S^{\prime}\right]$ and $i \in S \cap S^{\prime}$, either $[X, S] P_{i}\left[X^{\prime}, S^{\prime}\right]$ or $\left[X^{\prime}, S^{\prime}\right] P_{i}[X, S]$.

(C2) Indifference: For all $X \subset K$ and $S \subsetneq N, i \notin S$ if and only if $[X, S] I_{i}[X, \emptyset]$. Moreover, for all $X, X^{\prime} \in 2^{K},[X, \emptyset] I_{i}\left[X^{\prime}, \emptyset\right]$.

(C3) Loneliness: $[\emptyset,\{i\}] P_{i}[\emptyset, \emptyset]$.

(C4) Monotonicity: For all $X \subset K$ and all $S \subsetneq S^{\prime} \subset N$ such that $i \in S$, $\left[X, S^{\prime}\right] P_{i}[X, S]$.

(C5) Additivity: There exists $u_{i}: N \cup K \cup \emptyset \rightarrow \mathbb{R}$ such that $u_{i}(\emptyset)=0$ and for all $S, S^{\prime} \subset N$ and $X, X^{\prime} \subset K$

$[X, S] P_{i}\left[X^{\prime}, S^{\prime}\right]$ if and only if $\begin{cases}\sum_{j \in X \cup S} u_{i}(j)>\sum_{j \in X^{\prime} \cup S^{\prime}} u_{i}(j) & \text { when } i \in S \cap S^{\prime} \text {, and } \\ \sum_{j \in X \cup S} u_{i}(j)>0 & \text { when } i \in S \text { and } i \notin S^{\prime} .\end{cases}$

STRICTNESS means that member $i$ 's preference relation over final societies containing himself is strict. INDIFFERENCE says that if member $i$ is not in the society he is indifferent about who belongs to it. LONELINESS says that member $i$ finds specific benefits to being the only member of the society. Monotonicity means

\footnotetext{
${ }^{5}$ When considering $K$ as the set of issues that the society has to decide upon, the interpretation of a final society is the subset of approved issues and the subset of members that remain in the society.

${ }^{6}$ Concerning notation of sets' inclusion, we will use the symbol " $\subset$ " to denote the weak inclusion, that is, allowing for sets being equal. While we will use the symbol " $\subsetneq$ " to denote the strict inclusion, that is, to rule out the case where the sets are equal.
} 
that members consider the exit of other members undesirable, independently of the elected candidates. Notice that monotonicity does not impose any condition when comparing two final societies with different elected candidates. In particular, monotonicity admits the possibility that member $i$ prefers to belong to a smaller society. AdDITIVITY means that members' preferences are additively representable by utility functions. We denote by $\mathcal{R}_{i}$ the set of member $i$ 's preferences satisfying conditions (C1)-(C5) and by $\mathcal{R}$ the Cartesian product $\mathcal{R}_{1} \times \cdots \times \mathcal{R}_{n}$.

Before finishing this section, few comments about some of these assumptions are in order. While in some particular cases loneliness may be a strong requirement, there are many interesting problems for which it is very natural. For example, if the society is a provider of an excludable public good to its members, and the cost of producing it is small, loneliness requires that each agent is willing to produce (and consume) the public good by himself, even if he has to pay for the full cost. Observe that this is consistent with monotonicity if, for example, the cost of the public good is equally shared among all of its users. Societies sharing a collective TV antenna, or an elevator, or a gardener, or a swimming-pool may be instances where loneliness is a reasonable assumption. Note that under monotonicity, loneliness implies non-initial exit; that is, $[\emptyset, N] P_{i}[\emptyset, \emptyset]$. However, the converse is not true. Notice also that under additivity, the strictness condition implies that $u_{i}(x) \neq 0$ for all $x \in K \cup N \backslash\{i\}$. Then, by loneliness, $u_{i}(i)>0$ for all $i \in N$ and by monotonicity, $u_{i}(j)>0$ for all $j \in N \backslash\{i\}$. Moreover, under additivity the set of candidates can be partitioned into two disjoint sets. We say that candidate $x$ is good for member $i$ according to $R_{i}$ whenever $u_{i}(x)>0$; otherwise, we say that candidate $x$ is bad for member $i$ according to $R_{i}$. Denote by $G\left(R_{i}\right)$ and $B\left(R_{i}\right)$ the set of good and bad candidates for $i$ according to $R_{i}$, respectively.

\section{Voting by Committees with Exit}

In this paper we depart from Berga, Bergantiños, Massó, and Neme (2006) and we define the following two-stage game. First, members choose a subset of candidates with a given voting by committees. Second, and after knowing the elected candidates, members decide whether to stay or exit the society. In this setting we are interested in identifying a meaningful undominated Nash equilibrium in pure strategies of this two-stage game. 


\subsection{Voting by Committees}

Following Barberà, Sonnenschein, and Zhou (1991), a voting by committees is defined by a collection of families of winning coalitions (committees), one for each candidate, $\mathcal{W}=\left(\mathcal{W}_{x}\right)_{x \in K}$. Members vote for a subset of candidates. To be elected, a candidate must get the vote of all members of some coalition among those that are winning for that candidate. Formally, a committee for $x \in K$, denoted by $\mathcal{W}_{x}$, is a non-empty family of non-empty coalitions of $N$ satisfying coalition monotonicity $\left(S \in \mathcal{W}_{x}\right.$ and $S \subset T$ imply $T \in \mathcal{W}_{x}$ ). Given a committee $\mathcal{W}_{x}$ its set of minimal winning coalitions is $\mathcal{W}_{x}^{m} \equiv\left\{S \in \mathcal{W}_{x} \mid T \notin \mathcal{W}_{x}\right.$ for all $\left.T \subsetneq S\right\}$. Then, a mapping $v:\left(2^{K}\right)^{N} \rightarrow 2^{K}$ is voting by committees if there exists $\mathcal{W}=\left(\mathcal{W}_{x}\right)_{x \in K}$ such that for all $V=\left(V_{1}, \ldots, V_{n}\right) \in\left(2^{K}\right)^{N}$ and all $x \in K$,

$$
x \in v(V) \Longleftrightarrow\left\{i \in N \mid x \in V_{i}\right\} \in \mathcal{W}_{x} .
$$

We say that $v$ has no vetoers if the corresponding committees $\mathcal{W}=\left(\mathcal{W}_{x}\right)_{x \in K}$ have the property that for all $x \in K$ and all $i \in N$ there exists $S \in \mathcal{W}_{x}^{m}$ such that $i \notin S$. We say that member $i$ is a dummy for candidate $x$ according to $v$ if there does not exist $S \in \mathcal{W}_{x}^{m}$ such that $i \in S$. Given an integer $1 \leq q \leq n$, a voting by committees $v$ is voting by quota $q$ if for all $V=\left(V_{1}, \ldots, V_{n}\right) \in\left(2^{K}\right)^{N}$ and $x \in K$,

$$
x \in v(V) \text { if and only if } \#\left\{i \in N \mid x \in V_{i}\right\} \geq q,
$$

where \# stands for the cardinality of a set.

Barberà, Sonnenschein, and Zhou (1991) show that without exit, voting by committees constitute the full class of strategy-proof and onto social choice functions on the domain of both additive and separable preferences over all subsets of candidates. Berga, Bergantiños, Massó, and Neme (2004) show that social choice functions that are strategy-proof, stable, and satisfy founders' sovereignty on the set of candidates must be voting by committees and must satisfy the extreme condition that each member is a vetoer of all candidates. Hence, voting by quota $n$ is the unique strategy-proof and stable social choice function that satisfies founders' sovereignty on the set of candidates.

\subsection{Exit}

Assume that the set of candidates $X \in 2^{K}$ has already been elected and all members know that. Now, each member has to decide whether or not to continue in the 
society. But often, societies do not clearly specify the rules under which this exit takes place. Therefore, and to avoid to go into the specific details of these exit decisions (the order in which members have to decide as well as their information about the others' decisions), we recursively define (following Berga, Bergantiños, Massó, and Neme, 2005) the set of members leaving the society after $X$ is chosen.

Define first the set $E A^{1}(X)$ as the subset of members that unambiguously want to leave the society as the consequence of $X$ being chosen; that is, $E A^{1}(X)=$ $\left\{i \in N \mid[X, N \backslash\{i\}] P_{i}[X, N]\right\}$, or equivalently, $\left\{i \in N \mid[X, \emptyset] P_{i}[X, N]\right\}$. Let $t \geq 1$ and assume $E A^{t^{\prime}}(X)$ has been defined for all $t^{\prime}$ such that $1 \leq t^{\prime} \leq t$. Then,

$$
E A^{t+1}(X)=\left\{i \in N \backslash\left(\bigcup_{t^{\prime}=1}^{t} E A^{t^{\prime}}(X)\right) \mid[X, \emptyset] P_{i}\left[X, N \backslash\left(\bigcup_{t^{\prime}=1}^{t} E A^{t^{\prime}}(X)\right)\right]\right\} .
$$

Let $t_{X}$ be either equal to 1 if $E A^{1}(X)=\emptyset$ or else be the smallest positive integer satisfying the property that $E A^{t_{X}}(X) \neq \emptyset$ but $E A^{t_{X}+1}(X)=\emptyset$. Then, define the exit set after $X$ is chosen as $E A(X)=\bigcup_{t=1}^{t_{X}} E A^{t}(X)$ and the exit function as $E A: 2^{K} \rightarrow 2^{N}$.

Observe that this set only depends on the preference profile $R$. Motivation and some of its properties can be found in Berga, Bergantiños, Massó, and Neme (2006). In particular, $E A(X)$ is the set of members leaving the society after $X$ is chosen if exit is sequential (and members play according to the unique subgame perfect Nash equilibrium in pure strategies of the subgame starting at $X$ ); moreover, this set is independent of the ordering in which members decide (sequentially) whether to stay or to exit. The set $E A(X)$ also coincides with the set of members leaving the society if exit is simultaneous and members eliminate iteratively dominated strategies.

\subsection{The Game}

Fix a preference profile $R \in \mathcal{R}$. Given any voting by committees $v$ and the exit function $E A: 2^{K} \rightarrow 2^{N}$, we can model our two-stage game as the normal form game $\left(N,\left(2^{K}\right)^{N}, v, R\right)$. Given a strategy profile $V=\left(V_{1}, \ldots, V_{n}\right) \in\left(2^{K}\right)^{N}$ the final society is $v(V) \cup[N \backslash E A(v(V))]$. Since $N$ and $K$ are fixed we denote this game, given $v$ and $R$, by $\Gamma(v, R)$. To simplify notation, given a subset of candidates $X \subset K$ we use the notation $f(X)$ to express the final society when the set of candidates $X$ enter the society and the exit is given by $E A(X)$; i.e., $f(X)=X \cup(N \backslash E A(X))$. 
In addition and abusing notation, ${ }^{7}$ define for each $V \in\left(2^{K}\right)^{N}$,

$$
u_{i}(V)= \begin{cases}\sum_{j \in f(v(V))} u_{i}(j) & \text { if } i \notin E A(v(V)) \\ 0 & \text { if } i \in E A(v(V)) .\end{cases}
$$

In the current paper, as in Berga, Bergantiños, Massó, and Neme (2006), we are interested in equilibria in pure strategies. Observe that a Nash equilibrium $V^{*}$ of $\Gamma(v, R)$ implicitly assumes that members, through $(E A(X))_{X \in 2^{K}}$, have a minimal rational behavior in all subgames starting at any $X$ (subgame perfection, for instance, if exit is sequential).

In Example 7 in Berga, Bergantiños, Massó, and Neme (2006), the authors show that the set of undominated Nash equilibria in pure strategies of $\Gamma(v, R)$ might be empty. We reproduce here their Example, for sake of completeness and to point out some clues for solving the existence problem.

Example 1 Consider a society $N=\{1,2,3,4\}$, whose members have to decide whether or not to admit as new members candidates $x$ and $y$; that is, $K=\{x, y\}$. Assume that $v$ is voting by quota 1 . Consider the additive preference profile $R \in \mathcal{R}$ represented by the utility functions $u_{i}: N \cup K \cup \emptyset \rightarrow \mathbb{R}$ given by the following table:

\begin{tabular}{|c|c|c|c|c|}
\hline & $u_{1}$ & $u_{2}$ & $u_{3}$ & $u_{4}$ \\
\hline 1 & 100 & 5 & 1 & 1 \\
\hline 2 & 5 & 100 & 2 & 2.1 \\
\hline 3 & 1.1 & 100 & 1 & 3 \\
\hline 4 & 100 & 1.1 & 4 & 3 \\
\hline$x$ & 2 & -1 & -10 & -5 \\
\hline$y$ & -1 & 2 & -20 & -5.2 \\
\hline
\end{tabular}

It is straightforward to check that $E A(\emptyset)=\emptyset, E A(\{x\})=\{3\}, E A(\{y\})=\{3\}$, and $E A(\{x, y\})=\{3,4\}$. Then, for member $1,\{y\}$ is dominated by $\emptyset$ and $\{x, y\}$ is dominated by $\{x\}$. For member $2,\{x\}$ is dominated by $\emptyset$ and $\{x, y\}$ is dominated by $\{y\}$. For members 3 and $4,\{x\},\{y\}$, and $\{x, y\}$ are dominated by $\emptyset$. Therefore, the undominated strategies are $\{x\}$ and $\emptyset$ for member $1 ;\{y\}$ and $\emptyset$ for member $2 ; \emptyset$ for member 3 ; and $\emptyset$ for member 4 . The next table lists all possible strategy profiles

\footnotetext{
${ }^{7}$ We use the same notation $u_{i}$ for the utility function of member $i$ in the game $\Gamma(v, R)$ and the function representing the additive preference of member $i$. The reader will not be confused because from the context it will be clear which one of the two usages we are referring to.
} 
with undominated strategies, and their corresponding final societies.

\begin{tabular}{|l|l|}
\hline Voting & Final society \\
\hline$(\emptyset, \emptyset, \emptyset, \emptyset)$ & {$[\emptyset, N]$} \\
\hline$(\emptyset,\{y\}, \emptyset, \emptyset)$ & {$[\{y\},\{1,2,4\}]$} \\
\hline$(\{x\}, \emptyset, \emptyset, \emptyset)$ & {$[\{x\},\{1,2,4\}]$} \\
\hline$(\{x\},\{y\}, \emptyset, \emptyset)$ & {$[\{x, y\},\{1,2\}]$} \\
\hline
\end{tabular}

We now check that none of the four strategy profiles are Nash equilibria of $\Gamma(v, R)$.

1. $(\emptyset, \emptyset, \emptyset, \emptyset)$ is not an equilibrium. Since $[\{x\},\{1,2,4\}] P_{1}[\emptyset, N]$, member 1 improves by voting $\{x\}$.

2. $(\emptyset,\{y\}, \emptyset, \emptyset)$ is not an equilibrium. Since $[\emptyset, N] P_{2}[\{y\},\{1,2,4\}]$, member 2 improves by voting $\emptyset$.

3. $(\{x\}, \emptyset, \emptyset, \emptyset)$ is not an equilibrium. Since $[\{x, y\},\{1,2\}] P_{2}[\{x\},\{1,2,4\}]$, member 2 improves by voting $\{y\}$.

4. $(\{x\},\{y\}, \emptyset, \emptyset)$ is not an equilibrium. Since $[\{y\},\{1,2,4\}] P_{1}[\{x, y\},\{1,2\}]$, member 1 improves by voting $\emptyset$.

Therefore, the set of undominated pure strategy Nash equilibria of $\Gamma(v, R)$ is empty.

This example gives us some clues that suggest us to consider the domain restriction introduced in the next section. Note that both members 3 and 4 want that nobody enters. Members 1 and 2 have conflicting points of view that provoke the following cycle. Nobody entering the society is not a Nash equilibrium because member 1 prefers that $x$ enters. Only $x$ entering the society is not a Nash equilibrium because 2 prefers that $y$ also enters. Both candidates $x$ and $y$ entering the society is not a Nash equilibrium because 1 prefers that $x$ does not enter. Only $y$ entering the society is not a Nash equilibrium because 2 prefers that $y$ does not enter.

Although 4 and $x$ are good for member 1, 4 is more important. Member 1 knows that 4 leaves the society when both candidates enter and that 4 stays otherwise. Thus, 1 prefers to vote for $x$ when nobody enters and to vote for nobody when $y$ enters. Then, the cycle is caused, partially, because of the preferences of 4 .

Looking at the preferences of the other members we realize that, independently of the candidates entering the society, 1 and 2 never exit. Member 3 exits when some 
candidate enters. Therefore, bad candidates of 1, 2, and 3 can be classified in two categories: extremely bad and mildly bad. ${ }^{8}$ A bad candidate is extremely bad for member $i$ if his entrance makes the society to be, in any circumstance, undesirable for $i$. Candidates $x$ and $y$ are extremely bad for 3. A bad candidate is mildly bad for member $i$ if his entrance does not affect his exit decision. Candidate $x$ is mildly bad for 2 and $y$ is mildly bad for 1 . Nevertheless, $x$ and $y$ are neither extremely bad nor mildly bad for 4 .

If we modify the utility function of 4 in order to make candidates $x$ and $y$ extremely bad or mildly bad we realize that it is possible to find an undominated pure strategy Nash equilibrium. Taking $u_{4}(x)=-20$ and $u_{4}(y)=-30$ (both are extremely bad), $(\emptyset, \emptyset, \emptyset, \emptyset)$ is an undominated Nash equilibria. Taking $u_{4}(x)=-0.5$ and $u_{4}(y)=-30$ ( $x$ is mildly bad and $y$ is extremely bad), $(\{x\},\{y\}, \emptyset, \emptyset)$ is an undominated Nash equilibria. Taking $u_{4}(x)=-20$ and $u_{4}(y)=-0.7$ ( $x$ is extremely bad and $y$ is mildly bad), $(\emptyset, \emptyset, \emptyset, \emptyset)$ is an undominated Nash equilibria. Taking $u_{4}(x)=-0.5$ and $u_{4}(y)=-0.7$ (both are mildly bad), $(\{x\},\{y\}, \emptyset, \emptyset)$ is an undominated Nash equilibria. ${ }^{9}$

In the remainder of the paper we show that the game $\Gamma(v, R)$ has undominated Nash equilibria in pure strategies whenever each agent's preference $R_{i}$ satisfies the property of having dichotomous bads; that is, when bad candidates can be classified in extremely bad or mildly bad. We will show the existence of undominated Nash equilibria by constructing a particular and meaningful voting pure strategy profile.

\section{Dichotomous Bads}

There are societies whose members clearly distinguish among bad candidates according to how their election would influence the exit decisions. Let $x$ be a potential candidate. Imagine that member $i$ highly dislikes $x$ in such a way that $i$ will leave the society if $x$ is chosen even in the best situation where all the other elected candidates are good for $i$. In this case, we say that $x$ is an extremely bad candidate for member $i$, who will exit for sure if $x$ is elected. For instance, abortion, death penalty, tax reform, and a military intervention in another country could be extremely bads

\footnotetext{
${ }^{8}$ See Definitions 1 and 2 below for a formal statement of their meaning.

${ }^{9}$ The set of Nash equilibria of $\Gamma(v, R)$ is equal to $\left\{\left(V_{1}, V_{2}, V_{3}, V_{4}\right) \in\left(2^{K}\right)^{N} \mid \#\left\{i \in N \mid x \in V_{i}\right\} \geq 2\right.$ and $\left.\#\left\{i \in N \mid y \in V_{i}\right\} \geq 2\right\} \cup\{\{y\},\{y\},\{y\},\{y\}\}$.
} 
in our alternative interpretation of the set $K$ as issues. Member $i$ may also dislike another candidate $y$. However, while the election of $x$ would trigger his exit, the election of $y$ is never decisive in his exit. In such a case we say that $y$ is a mildly bad candidate for $i$ (in the alternative interpretation of candidates as issues, $y$ could be a very local policy on public transportation). Formally,

Definition 1 Given member $i$ 's preference $R_{i} \in \mathcal{R}_{i}$, we say that the bad candidate $x \in B\left(R_{i}\right)$ is extremely bad for $i$ if $\left[G\left(R_{i}\right) \cup\{x\}, \emptyset\right] P_{i}\left[G\left(R_{i}\right) \cup\{x\}, N\right]$.

Definition 2 Given member $i$ 's preference $R_{i} \in \mathcal{R}_{i}$, we say that the bad candidate $x \in B\left(R_{i}\right)$ is mildly bad for $i$ if for all $X \in 2^{K}$ such that $[X,\{i\}] P_{i}[X, \emptyset]$, we have $[X \cup\{x\},\{i\}] P_{i}[X \cup\{x\}, \emptyset]$.

Given $R_{i} \in \mathcal{R}_{i}$, denote the set of extremely bad candidates for $i$ by $B^{--}\left(R_{i}\right)$ and the set of mildly bad candidates for $i$ by $B^{-}\left(R_{i}\right)$.

Remark 1 The society formed by member $i$ and her set of mildly bad candidates is, by its definition, acceptable for member $i$, that is, $\left[B^{-}\left(R_{i}\right),\{i\}\right] P_{i}\left[B^{-}\left(R_{i}\right), \emptyset\right]$.

Remark 2 For all $R_{i} \in \mathcal{R}_{i}, B^{--}\left(R_{i}\right) \cap B^{-}\left(R_{i}\right)=\emptyset$.

Preferences with dichotomous bads are those where bads are either of the type that they are pivotal in triggering exit regardless of the combination of other candidates or they are of the type that they are not pivotal triggering exit by themselves. Hence preferences that do not have dichotomous bads are those where there may be bads that are not pivotal by themselves but are pivotal when taken in combination with some other candidates. Namely,

Definition 3 A preference relation $R_{i} \in \mathcal{R}_{i}$ has dichotomous bads if $B\left(R_{i}\right)=$ $B^{--}\left(R_{i}\right) \cup B^{-}\left(R_{i}\right)$.

Let $\mathcal{D}_{i} \subset \mathcal{R}_{i}$ be the subset of member $i$ 's preferences with dichotomous bads and let $\mathcal{D}$ denote the Cartesian product $\mathcal{D}_{1} \times \cdots \times \mathcal{D}_{n}$.

To illustrate the definition of a preference relation with dichotomous bads consider again Example 1, in which $R_{1}, R_{2}$, and $R_{3}$ have dichotomous bads, but as we have already mentioned, $R_{4} \in \mathcal{R}_{4}$ does not. First, $B^{--}\left(R_{4}\right)=\emptyset$ since $[\{x\}, N] P_{4}[\{x\}, \emptyset]$ and $[\{y\}, N] P_{4}[\{y\}, \emptyset]$. Nevertheless, its complementary set of bads $B\left(R_{4}\right) \backslash B^{--}\left(R_{4}\right)=\{x, y\}$ has the property that $[\{x, y\}, \emptyset] P_{4}[\{x, y\},\{4\}]$, which means that $B^{-}\left(R_{4}\right) \neq\{x, y\}$. In fact, $B^{-}\left(R_{4}\right)=\emptyset$.

Next proposition characterizes $B^{--}\left(R_{i}\right)$ and $B^{-}\left(R_{i}\right)$ in terms of the exit function $E A: 2^{K} \rightarrow 2^{N}$. It says that the entrance of an extremely bad candidate always 
leads to the exit of member $i$ whereas the entrance of a mildly bad candidate does not affect the exit of $i$.

Proposition 1 Let $i \in N$ and $R_{i} \in \mathcal{D}_{i}$. Then,

$$
\begin{aligned}
B^{--}\left(R_{i}\right) & =\left\{x \in B\left(R_{i}\right) \mid i \in E A(X) \text { whenever } x \in X \subset K\right\} \text { and } \\
B^{-}\left(R_{i}\right) & =\left\{x \in B\left(R_{i}\right) \mid \text { for all } X \in 2^{K},[i \in E A(X \cup\{x\}) \Leftrightarrow i \in E A(X)]\right\} .
\end{aligned}
$$

Proof See Appendix A.

We now establish some useful properties of the exit function $E A: 2^{K} \rightarrow 2^{N}$ for the domain of preferences with dichotomous bads $\mathcal{D}$.

Proposition 2 Let $R=\left(R_{1}, \ldots, R_{n}\right) \in \mathcal{D}$.

(2.1) Then, $E A(A)=\cup_{x \in A} E A(x)$ for all $A \subset K$.

(2.2) Assume $A, B, C \subset K$ are such that $A \subset B$ and $B \cap C=\emptyset$. Then, $E A(B \cup C) \backslash$ $E A(B) \subset E A(A \cup C) \backslash E A(A)$.

(2.3) Assume $A, B, C \subset K$ are such that $A \subset B$ and $B \cap C=\emptyset$. Then,

$$
\sum_{j \in f(B \cup C)} u_{i}(j)-\sum_{j \in f(B)} u_{i}(j) \geq \sum_{j \in f(A \cup C)} u_{i}(j)-\sum_{j \in f(A)} u_{i}(j) .
$$

Proof See Appendix B.

Property (2.2) says that the exit produced by the additional entrance of new candidates $(C)$ is larger the smaller is the set of elected candidates. Property (2.3) says that there are increasing returns to scale in the sense that the larger the set of elected candidates is the larger is the interest of members to accept new subsets of candidates.

\section{An undominated Nash equilibrium}

Let $\mathcal{W}=\left(\mathcal{W}_{x}\right)_{x \in K}$ be the set of families of winning coalitions defining the voting by committees $v$ and let $R=\left(R_{1}, \ldots, R_{n}\right) \in \mathcal{D}$. To construct an undominated Nash equilibrium in pure strategies of $\Gamma(v, R)$ we first consider the following process which may be understood as if each member would vote for candidates in successive stages.

- Stage 1: For all $i \in N$ define the set $\bar{V}_{i}^{1}$ as the best subset of candidates that member $i$ would like to admit taking into account the exit it would induce. Formally,

$$
\bar{V}_{i}^{1}=\left\{X \in 2^{K} \mid f(X) P_{i} f\left(X^{\prime}\right) \text { for all } X^{\prime} \subset K \text { such that } X^{\prime} \neq X\right\} .
$$


By strictness and $E A(\emptyset)=\emptyset, \bar{V}_{i}^{1}$ is well defined and it contains a unique subset (possibly the empty set). Moreover,

$$
f\left(\bar{V}_{i}^{1}\right) R_{i}[\emptyset, N] P_{i}\left[\bar{V}_{i}^{1}, \emptyset\right] .
$$

Therefore, $i \notin E A\left(\bar{V}_{i}^{1}\right)$. Set

$$
\begin{aligned}
& V_{i}^{1}=\bar{V}_{i}^{1}, \\
& \bar{V}^{1}=\left\{x \in K \mid\left\{i \in N \mid x \in \bar{V}_{i}^{1}\right\} \in \mathcal{W}_{x}\right\}, \text { and } \\
& V^{1}=\bar{V}^{1} .
\end{aligned}
$$

Notice that $\bar{V}^{1}=v\left(\left(\bar{V}_{i}^{1}\right)_{i \in N}\right)$; i.e., $\bar{V}^{1}$ is the set of elected candidates when members vote $\left(\bar{V}_{i}^{1}\right)_{i \in N}$.

- Stage t+1: Assume that $\bar{V}_{i}^{r}, \bar{V}^{r}, V_{i}^{r}$, and $V^{r}$ have been defined for all $r \leq t$ and all $i \in N$, and $f\left(V^{t}\right) P_{i}\left[V^{t}, \emptyset\right]$ when $i \notin E A\left(V^{t}\right)$. We will define $\bar{V}_{i}^{t+1}$ and $V_{i}^{t+1}$ for all $i \in N$, and $\bar{V}^{t+1}$ and $V^{t+1}$.

If $i \in E A\left(V^{t}\right)$, by property (2.1), there exists $x \in V^{t} \cap B^{--}\left(R_{i}\right)$ such that $i \in E A(x)$. Therefore, $i \in E A\left(V^{t} \cup X\right)$ for all $X \subset K \backslash V^{t}$. In this case we take $\bar{V}_{i}^{t+1}=\bar{V}_{i}^{t}$.

If $i \notin E A\left(V^{t}\right)$ then,

$\bar{V}_{i}^{t+1}=\left\{X \subset K \backslash V^{t} \mid f\left(V^{t} \cup X\right) P_{i} f\left(V^{t} \cup X^{\prime}\right)\right.$ for all $X^{\prime} \subset K \backslash V^{t}$ s.t. $\left.X^{\prime} \neq X\right\}$.

By strictness, $\bar{V}_{i}^{t+1}$ is well defined and it contains a unique subset (possibly the empty set). Moreover,

$$
f\left(V^{t} \cup \bar{V}_{i}^{t+1}\right) R_{i} f\left(V^{t}\right) P_{i}\left[V^{t}, \emptyset\right] .
$$

Therefore, $i \notin E A\left(V^{t} \cup \bar{V}_{i}^{t+1}\right)$. Given $V^{t}$, the set $\bar{V}_{i}^{t+1}$ is the best subset of candidates that member $i$ would like to admit, once the set $V^{t}$ has already been elected, taking into account the exit it would induce. Set

$$
\begin{aligned}
V_{i}^{t+1} & =\cup_{r=1}^{t+1} \bar{V}_{i}^{r}, \\
\bar{V}^{t+1} & =\left\{x \in K \backslash V^{t} \mid\left\{i \in N \mid x \in \bar{V}_{i}^{t+1}\right\} \in \mathcal{W}_{x}\right\}, \text { and } \\
V^{t+1} & =\cup_{r=1}^{t+1} \bar{V}^{r} .
\end{aligned}
$$

The set $V_{i}^{t+1}$ represents the candidates voted by $i$ in stages $1, \ldots, t+1$ while $\bar{V}^{t+1}$ represents the candidates joining the society when members vote $\left(\bar{V}_{i}^{t+1}\right)_{i \in N}$. Finally, $V^{t+1}$ represents the candidates joining the society in stages $1, \ldots, t+1$. 
This process ends either at $T=1$ if $V^{1}=\emptyset$ or at $T \geq 2$ when there exists such $T$ satisfying $\bar{V}^{T-1} \neq \emptyset$ and $\bar{V}^{T}=\emptyset$. The following example illustrates this construction.

Example 2 Let $N=\{1,2,3\}$ be a society and let $K=\{x, y\}$ be the set of candidates. Assume that $v$ is voting by quota 1 . Consider the additive preference profile $R=\left(R_{1}, R_{2}, R_{3}\right) \in \mathcal{R}$ represented by the following utility functions:

\begin{tabular}{|c|c|c|c|}
\hline & $u_{1}$ & $u_{2}$ & $u_{3}$ \\
\hline 1 & 10 & 3 & 1 \\
\hline 2 & 1 & 10 & 2 \\
\hline 3 & 100 & 1 & 3 \\
\hline$x$ & 2 & 11 & -7 \\
\hline$y$ & 4 & -2.1 & -7 \\
\hline
\end{tabular}

Note that $R \in \mathcal{D}$. Moreover, $B^{--}\left(R_{1}\right)=B^{-}\left(R_{1}\right)=\emptyset, B^{--}\left(R_{2}\right)=\emptyset, B^{-}\left(R_{2}\right)=$ $\{y\}, B^{--}\left(R_{3}\right)=\{x, y\}$, and $B^{-}\left(R_{3}\right)=\emptyset$. We now compute $\bar{V}_{i}^{t}$ for all $i$ and $t$.

\begin{tabular}{|l|l|l|l|}
\hline$t \backslash i$ & 1 & 2 & 3 \\
\hline $\bar{V}_{i}^{1}$ & $\emptyset$ & $x$ & $\emptyset$ \\
\hline $\bar{V}_{i}^{2}$ & $y$ & $\emptyset$ & $\emptyset$ \\
\hline $\bar{V}_{i}^{3}$ & $\emptyset$ & $\emptyset$ & $\emptyset$ \\
\hline
\end{tabular}

Then, $T=3, V_{1}^{3}=\{y\}, V_{2}^{3}=\{x\}$, and $V_{3}^{3}=\emptyset$. Observe that initially member 1 is not interested in the entrance of any of the two candidates since they produce the exit of member 3. But, once $x$ is elected (member 2 likes him very much) and thus, member 3 exits, then member 1 wants $y$ to be elected. Therefore, along the process, member 1 has only voted for $y$ which is dominated by voting for both $(x$ and $y)$.

To avoid this, and since our objective is to identify an undominated pure strategy Nash equilibrium, we modify the process by adding to each $V_{i}^{T}$ the best subset $H_{i}$ (taking into account its effects on the exit of other members) of the set $A_{i}$ of good candidates that $i$ has not voted for along the process but have joined the society before $i$ exits. Formally, for each $i \in N$,

$$
A_{i}= \begin{cases}G\left(R_{i}\right) \cap\left(V^{T-1} \backslash V_{i}^{T}\right) & \text { if } i \notin E A\left(V^{T}\right) \\ G\left(R_{i}\right) \cap\left(V^{t-1} \backslash V_{i}^{T}\right) & \text { if } i \notin E A\left(V^{t-1}\right) \text { and } i \in E A\left(V^{t}\right) \text { for some } t\end{cases}
$$

and

$$
H_{i}=\left\{X \subset A_{i} \mid f\left(V_{i}^{T} \cup X\right) P_{i} f\left(V_{i}^{T} \cup X^{\prime}\right) \text { for all } X^{\prime} \subset A_{i} \text { such that } X^{\prime} \neq X\right\} .
$$


We now prove that $H_{i}$ is well defined. By convention we set $V^{0}=\emptyset$. We first prove that $i \notin E A\left(V_{i}^{T}\right)$ considering two cases:

- Assume that $i \in E A\left(V^{T}\right)$. Then, there exists $h \in\{0, \ldots, T-1\}$ such that $i \notin E A\left(V^{h}\right)$ but $i \in E A\left(V^{h+1}\right)$. By the definition of the process $\bar{V}_{i}^{t}=\bar{V}_{i}^{h}$ for all $t=h+1, \ldots, T$ and $i \notin E A\left(V^{t} \cup \bar{V}_{i}^{t+1}\right)$ for all $t=0, \ldots, h$. Then, by property $(2.1), i \notin E A\left(\bar{V}_{i}^{t}\right)$ for all $t=1, \ldots, h+1$. Since $V_{i}^{T}=\cup_{t=1}^{h+1} \bar{V}_{i}^{t}$, by property $(2.1), i \notin E A\left(V_{i}^{T}\right)$.

- Assume now that $i \notin E A\left(V^{T}\right)$. By the definition of the process $i \notin E A\left(V^{t} \cup \bar{V}_{i}^{t+1}\right)$ for all $t=0, \ldots, T-1$. Then, by property $(2.1), i \notin E A\left(\bar{V}_{i}^{t}\right)$ for all $t=1, \ldots, T$. Since $V_{i}^{T}=\cup_{t=1}^{h+1} \bar{V}_{i}^{t}$, by property $(2.1), i \notin E A\left(V_{i}^{T}\right)$.

Notice that, by definition of $E A, f\left(V_{i}^{T}\right) P_{i}\left[V_{i}^{T}, \emptyset\right]$ because $i \notin E A\left(V_{i}^{T}\right)$. By strictness we conclude that $H_{i}$ is well defined, it is a singleton, and

$$
f\left(V_{i}^{T} \cup H_{i}\right) R_{i} f\left(V_{i}^{T}\right) P_{i}\left[V_{i}^{T}, \emptyset\right] .
$$

Using the process defined above, we now define the vote of each member $i \in N$ by

$$
Z_{i}=V_{i}^{T} \cup H_{i}
$$

Remark 3 By definition of $E A, f\left(Z_{i}\right) P_{i}\left[Z_{i}, \emptyset\right]$ implies that $i \notin E A\left(Z_{i}\right)$ for all $i \in N$.

Next proposition states two properties of the procedure defining $Z=\left(Z_{i}\right)_{i \in N}$. First, if member $i$ votes for candidate $x$ in stage $t, i$ will vote for $x$ in any later stage $t^{\prime}>t$, whenever $x$ has not been elected yet. Second, when members vote $\left(V_{i}^{T}\right)_{i \in N}$ the set of elected candidates coincides with the set of elected candidates when members vote $\left(Z_{i}\right)_{i \in N}$.

Proposition 3 Let $R \in \mathcal{D}$. Then,

(3.1) For all $i \in N$ and $1 \leq t \leq T-1$, if $x \in \bar{V}_{i}^{t}$ then, $x \in \bar{V}_{i}^{t^{\prime}}$ for any $t^{\prime}>t$ whenever $x \notin V^{t^{\prime}-1}$.

(3.2) $v\left(\left(V_{i}^{T}\right)_{i \in N}\right)=v\left(\left(Z_{i}\right)_{i \in N}\right)=V^{T}$.

Proof See Appendix C.

Observe that, as a consequence of property (3.1), given $i \in N$ and $1 \leq t \leq t^{\prime} \leq T$, $\bar{V}_{i}^{t} \subset V^{t^{\prime}} \cup \bar{V}_{i}^{t^{\prime}}$

Theorem 1 below states our main result of the paper: if the society selects the candidates to become new members by a voting by committees $v$ without vetoers 
and members follow the exit procedure given by $E A,\left(Z_{1}, \ldots, Z_{n}\right)$ is an undominated Nash equilibrium of $\Gamma(v, R)$.

Theorem 1 Assume $R \in \mathcal{D}$ and let $v$ be a voting by committees without vetoers. Then, $\left(Z_{1}, \ldots, Z_{n}\right)$ is an undominated Nash equilibrium of $\Gamma(v, R)$.

Proof See Appendix D.

The proof of Theorem 1 is involved and hard to follow. The main reason is that the identification of the strategy profile $Z=V^{T} \cup H$ is based on a recursive construction (to obtain $V^{T}$ ) that has to be further modified to include the vote for some (unvoted) good candidates $(H)$. Hence, our arguments are less transparent than we would like because they are often indirect and/or inductive. However, the main arguments of the proof are the following. First, we show by contradiction that for each $i \in N, Z_{i}$ is an undominated strategy (see Lemma 3). Suppose that for $i \in N$, there exists an strategy $V_{i}^{\prime}$ that dominates $Z_{i}$. Then, we show both that

$$
Z_{i} \subset V_{i}^{\prime}
$$

and

$$
V_{i}^{\prime} \cap\left(K \backslash Z_{i}\right)=\emptyset
$$

Observe that (1) and (2) imply $V_{i}^{\prime}=Z_{i}$. To obtain condition (1), and since by definition, $Z_{i}=V_{i}^{T} \cup H_{i}$, we first show (using an induction argument on $t$ ) that $V_{i}^{T} \subset V_{i}^{\prime}$ and then that $H_{i} \subset V_{i}^{\prime}$. Condition (2) is obtained by contradiction after distinguishing between two kind of strategies depending on the exit decision of $i$ (that is, $i \in E A\left(V^{T}\right)$ and $i \notin E A\left(V^{T}\right)$ ). Second, in Lemma 4, we show that $Z$ is a Nash equilibrium strategy by showing that for all $i \in N, Z_{i}$ is a best response given $Z_{-i}$. And we do so by distinguishing between the same two kind of strategies used above that depends on the exit decision of $i$.

Next example shows that there might be other undominated Nash equilibrium strategies different from $\left(Z_{1}, \ldots, Z_{n}\right)$.

Example 3 Let $N=\{1,2,3\}$ be a society and let $K=\{x, y\}$ be the set of candidates. Assume that $v$ is voting by quota 1 . Consider the preference profile $R=\left(R_{1}, R_{2}, R_{3}\right) \in \mathcal{D}$ represented by the following utility functions: 


\begin{tabular}{|r|r|r|r|}
\hline & $u_{1}$ & $u_{2}$ & $u_{3}$ \\
\hline 1 & 10 & 4 & 1 \\
\hline 2 & 2 & 10 & 2 \\
\hline 3 & 20 & 8 & 2 \\
\hline$x$ & 4 & -1 & -10 \\
\hline$y$ & -1 & 2 & -10 \\
\hline
\end{tabular}

In this case $Z_{1}=Z_{2}=Z_{3}=\emptyset$. Consider the strategy profile $V^{\prime}=(\{x\},\{y\}, \emptyset)$. It is straightforward to show that $V^{\prime}$ is a Nash equilibrium of $\Gamma(v, R)$. Moreover, $\{x\}$ is undominated for member 1 because when member 2 votes $\{y\}$ the best reply of member 1 is to vote $\{x\}$. With similar arguments we can conclude that to vote $\{y\}$ is undominated for member 2 . Of course, $\emptyset$ is undominated for member 3 . Therefore, $V^{\prime}(\neq Z)$ is an undominated pure strategy Nash equilibrium of $\Gamma(v, R)$.

\section{Acknowledgements}

We are thankful to two anonymous referees for their very helpful comments and suggestions that helped us to write a better version of the paper. The work of A. Neme is partially supported by the Universidad Nacional de San Luis through Grant 319502, by the Consejo Nacional de Investigaciones Científicas y Técnicas CONICET, through Grant PICT-02114, and by the Agencia Nacional de Promoción Científica y Técnica, through Grant 03-10814. The work of D. Berga, G. Bergantiños, and J. Massó is partially supported by Research Grants SEJ200403276, SEJ2005-07637-C02-01, and SEJ2005-04081 from the Spanish Ministry of Education and Science, respectively. The work of G. Bergantiños is also partially supported by Research Grant PGIDIT06PXIC300184PN from the Xunta de Galicia. The work of D. Berga and J. Massó is also partially supported by Research Grants 2005SGR213 and SGR2005-00454, respectively, from the Generalitat de Catalunya. D. Berga and J. Massó also acknowledge financial support from the Barcelona Economics Program (CREA), Generalitat de Catalunya. J. Massó and A. Neme also acknowledge financial support from the grant PCI España-Iberoamérica 2006 (Programa de Cooperación Interuniversitaria de la Agencia Española de Cooperación Internacional - AECI). 


\section{Appendix A. Proof of Proposition 1}

Before proving Proposition 1, we establish a useful Lemma. Observe that monotonicity and loneliness imply $E A(\emptyset)=\emptyset$.

Lemma 1 Assume that $R_{i} \in \mathcal{D}_{i}$ and $i \in E A(X)$. Then, there exists $x \in X$ such that $x \in B^{--}\left(R_{i}\right)$.

Proof Since $i \in E A(X)=\cup_{t=1}^{T} E A^{t}(X)$ we conclude that $i \in E A^{t_{0}}(X)$ for some $t_{0} \leq T$ and hence,

$$
[X, \emptyset] P_{i}\left[X, N \backslash\left(\cup_{t=1}^{t_{0}-1} E A^{t}(X)\right)\right]
$$

Since preferences are monotonic,

$$
\left[X, N \backslash\left(\cup_{t=1}^{t_{0}-1} E A^{t}(X)\right)\right] R_{i}[X,\{i\}]
$$

By contradiction, assume that $X \cap B^{--}\left(R_{i}\right)=\emptyset$. Since $R_{i}$ has dichotomous bads,

$$
[X,\{i\}] R_{i}\left[B^{-}\left(R_{i}\right),\{i\}\right]
$$

By indifference and transitivity of $R_{i}$,

$$
\left[B^{-}\left(R_{i}\right), \emptyset\right] I_{i}[X, \emptyset] P_{i}\left[B^{-}\left(R_{i}\right),\{i\}\right]
$$

But this is a contradiction since $\left[B^{-}\left(R_{i}\right),\{i\}\right] P_{i}\left[B^{-}\left(R_{i}\right), \emptyset\right]$ by Remark 1 .

Proof of Proposition 1 We need to prove the following four statements:

(a) $B^{--}\left(R_{i}\right) \subset\left\{x \in B\left(R_{i}\right) \mid i \in E A(X)\right.$ whenever $\left.x \in X \subset K\right\}$.

Take $x \in B^{--}\left(R_{i}\right)$ and $X \subset K$ such that $x \in X$. By indifference,

$$
[X, \emptyset] I_{i}\left[G\left(R_{i}\right) \cup\{x\}, \emptyset\right]
$$

Since $x \in B^{--}\left(R_{i}\right)$,

$$
\left[G\left(R_{i}\right) \cup\{x\}, \emptyset\right] P_{i}\left[G\left(R_{i}\right) \cup\{x\}, N\right] .
$$

By additivity,

$$
\left[G\left(R_{i}\right) \cup\{x\}, N\right] R_{i}[X, N]
$$

where $R_{i}=I_{i}$ if $X=G\left(R_{i}\right) \cup\{x\}$ and $R_{i}=P_{i}$ if $X \neq G\left(R_{i}\right) \cup\{x\}$, by strictness. By transitivity, $[X, \emptyset] P_{i}[X, N]$. Hence, $i \in E A^{1}(X) \subset E A(X)$. 
(b) $\left\{x \in B\left(R_{i}\right) \mid i \in E A(X)\right.$ whenever $\left.x \in X \subset K\right\} \subset B^{--}\left(R_{i}\right)$.

Take $X=\{x\}$. Since $i \in E A(X)$, by Lemma 1 , there exists $y \in B^{--}\left(R_{i}\right) \cap X$. Then, $x \in B^{--}\left(R_{i}\right)$.

(c) $B^{-}\left(R_{i}\right) \subset\left\{x \in B\left(R_{i}\right) \mid\right.$ for all $\left.X \subset K,[i \in E A(X \cup\{x\}) \Leftrightarrow i \in E A(X)]\right\}$.

Take $x \in B^{-}\left(R_{i}\right)$ and $X \subset K$. We now prove that $i \in E A(X \cup\{x\})$ if and only if $i \in E A(X)$.

Assume that $i \in E A(X)$. Then, by Lemma 1, there exists $y \in X$ such that $y \in B^{--}\left(R_{i}\right)$. By (a), we conclude that $i \in E A(X \cup\{x\})$ because $y \in X \cup\{x\}$.

Assume that $i \in E A(X \cup\{x\})$. Then, by Lemma 1, there exists $y \in X \cup\{x\}$ such that $y \in B^{--}\left(R_{i}\right)$. Since $R_{i}$ has dichotomous bads and $x \in B^{-}\left(R_{i}\right)$ we conclude that $y \neq x$. Then, $y \in X \cap B^{--}\left(R_{i}\right)$ and hence $i \in E A(X)$ because of (a).

(d) $\left\{x \in B\left(R_{i}\right) \mid\right.$ for all $\left.X \subset K,[i \in E A(X \cup\{x\}) \Leftrightarrow i \in E A(X)]\right\} \subset B^{-}\left(R_{i}\right)$.

Since $R_{i}$ has dichotomous bads it is enough to prove that if $x \in B^{--}\left(R_{i}\right)$ then $x$ does not satisfy that for all $X \subset K, i \in E A(X)$ if and only if $i \in$ $E A(X \cup\{x\})$. Assume $X=\emptyset$. By loneliness and monotonicity, there is no initial exit; i.e., $E A(\emptyset)=\emptyset$ and hence $i \notin E A(\emptyset)$. But $i \in E A(\{x\})$ because $x \in B^{--}\left(R_{i}\right)$.

\section{Appendix B. Proof of Proposition 2}

Proof of Proposition 2 Let $i \in E A(A)$. By Lemma 1, there exists $x \in A \cap$ $B^{--}\left(R_{i}\right)$. By part (a) in the proof of Proposition $1, i \in E A(X)$ for every $X \subset K$ such that $x \in X$. Then, $i \in E A(x)$ and $E A(A) \subset \cup_{x \in A} E A(x)$. Now, assume that $i \in E A(x)$ with $x \in A$. Then, by Lemma $1, x \in B^{--}\left(R_{i}\right)$ and hence, by Proposition $1, i \in E A(A)$. This proves (2.1).

To prove properties (2.2) and (2.3) assume that $A, B, C \subset K$ are such that $A \subset B$ and $B \cap C=\emptyset$. By property (2.1), we have that $E A(B \cup C)=\bigcup_{x \in B \cup C} E A(x)$ and $E A(B)=\bigcup_{x \in B} E A(x)$. Note that $\bigcup_{x \in B \cup C} E A(x) \backslash \bigcup_{x \in B} E A(x)=\bigcup_{x \in C} E A(x) \backslash \bigcup_{x \in B} E A(x)$. Applying again property (2.1), we have that $E A(C)=\bigcup_{x \in C} E A(x)$ and $E A(B)=$ $\bigcup_{x \in B} E A(x)$. Thus,

$$
E A(B \cup C) \backslash E A(B)=E A(C) \backslash E A(B) .
$$


Using similar arguments, we also obtain that

$$
\begin{aligned}
E A(A \cup C) \backslash E A(A) & =\bigcup_{x \in A \cup C} E A(x) \backslash \bigcup_{x \in A} E A(x) \\
& =\bigcup_{x \in C} E A(x) \backslash \bigcup_{x \in A} E A(x) \\
& =E A(C) \backslash E A(A) .
\end{aligned}
$$

Because $E A(A) \subset E A(B),(3)$ and (4) imply that property (2.2) holds.

By definition of $f$ :

$$
\begin{aligned}
f(B \cup C) & =(B \cup C) \cup[N \backslash E A(B \cup C)] \\
f(B) & =B \cup[N \backslash E A(B)] \\
f(A \cup C) & =(A \cup C) \cup[N \backslash E A(A \cup C)] \\
f(A) & =A \cup[N \backslash E A(A)] .
\end{aligned}
$$

Thus,

$\sum_{j \in f(B \cup C)} u_{i}(j)-\sum_{j \in f(B)} u_{i}(j)=\sum_{j \in B \cup C} u_{i}(j)+\sum_{j \in N \backslash E A(B \cup C)} u_{i}(j)-\sum_{j \in B} u_{i}(j)-\sum_{j \in N \backslash E A(B)} u_{i}(j)$.

Because $B \cap C=\emptyset$ and $N \backslash E A(B) \subset N \backslash E A(B \cup C)$,

$$
\sum_{j \in f(B \cup C)} u_{i}(j)-\sum_{j \in f(B)} u_{i}(j)=\sum_{j \in C} u_{i}(j)-\sum_{j \in E A(B \cup C) \backslash E A(B)} u_{i}(j) .
$$

On the other hand,

$\sum_{j \in f(A \cup C)} u_{i}(j)-\sum_{j \in f(A)} u_{i}(j)=\sum_{j \in A \cup C} u_{i}(j)+\sum_{j \in N \backslash E A(A \cup C)} u_{i}(j)-\sum_{j \in A} u_{i}(j)-\sum_{j \in N \backslash E A(A)} u_{i}(j)$.

Because $A \cap C=\emptyset$ and $N \backslash E A(A) \subset N \backslash E A(A \cup C)$,

$$
\sum_{j \in f(A \cup C)} u_{i}(j)-\sum_{j \in f(A)} u_{i}(j)=\sum_{j \in C} u_{i}(j)-\sum_{j \in E A(A \cup C) \backslash E A(A)} u_{i}(j) .
$$

By monotonicity and property (2.2),

$$
\sum_{j \in C} u_{i}(j)-\sum_{j \in E A(B \cup C) \backslash E A(B)} u_{i}(j) \geq \sum_{j \in C} u_{i}(j)-\sum_{j \in E A(A \cup C) \backslash E A(A)} u_{i}(j) .
$$

Hence, property (2.3) holds.

\section{Appendix C. Proof of Proposition 3}

Proof of Proposition 3 (3.1) If $i \in E A\left(V^{t}\right)$ then, by the definition of the process, $\bar{V}_{i}^{t^{\prime}}=\bar{V}_{i}^{t}$ for all $t^{\prime}>t$. Hence, $x \in \bar{V}_{i}^{t^{\prime}}$.

Assume now that $i \notin E A\left(V^{t}\right)$ and let $t^{\prime}>t$. We consider two cases: 
- We first assume that $i \notin E A\left(V^{t^{\prime}-1}\right)$. Suppose that $x \notin \bar{V}_{i}^{t^{\prime}}$. Then, $Q=$ $\bar{V}_{i}^{t} \backslash\left(V^{t^{\prime}-1} \cup \bar{V}_{i}^{t^{\prime}}\right) \neq \emptyset$ because $x \in Q$. Applying property (2.3) in Proposition 2 when defining $A, B$, and $C$ as $V^{t-1} \cup\left(\bar{V}_{i}^{t} \backslash Q\right), V^{t^{\prime}-1} \cup \bar{V}_{i}^{t^{\prime}}$, and $Q$, respectively, we obtain that

$$
\begin{aligned}
& \sum_{j \in f\left(V^{t^{\prime}-1} \cup \bar{V}_{i}^{\left.t^{\prime} \cup Q\right)}\right.} u_{i}(j)-\sum_{j \in f\left(V^{t^{\prime}-1} \cup \bar{V}_{i}^{t^{\prime}}\right)} u_{i}(j) \geq \\
& \sum_{j \in f\left(V^{t-1} \cup \bar{V}_{i}^{t}\right)} u_{i}(j)-\sum_{j \in f\left(V^{t-1} \cup\left(\bar{V}_{i}^{t} \backslash Q\right)\right)} u_{i}(j)>0,
\end{aligned}
$$

where the last inequality comes from the definition of $\bar{V}_{i}^{t}$. Then,

$$
f\left(V^{t^{\prime}-1} \cup \bar{V}_{i}^{t^{\prime}} \cup Q\right) P_{i} f\left(V^{t^{\prime}-1} \cup \bar{V}_{i}^{t^{\prime}}\right)
$$

which contradicts the definition of $\bar{V}_{i}^{t^{\prime}}$.

- We now assume that $i \in E A\left(V^{t^{\prime}-1}\right)$. Let $t^{*}>t$ be such that $i \notin E A\left(V^{t^{*}}\right)$ but $i \in E A\left(V^{t^{*}+1}\right)$. We know that $t \leq t^{*}<t^{\prime}$ and $t^{\prime}>t+1$. Because of the previous case we know that $x \in \bar{V}_{i}^{t^{*}+1}$. By the definition of the process, $\bar{V}_{i}^{t^{\prime}}=\bar{V}_{i}^{t^{\prime}-1}=\ldots=\bar{V}_{i}^{t^{*}+1}$. Hence, $x \in \bar{V}_{i}^{t^{\prime}}$.

(3.2) We first prove that $v\left(\left(V_{i}^{T}\right)_{i \in N}\right)=V^{T}$. Of course, $V^{T} \subset v\left(\left(V_{i}^{T}\right)_{i \in N}\right)$.

We prove that $v\left(\left(V_{i}^{T}\right)_{i \in N}\right) \subset V^{T}$. Suppose that $x \in v\left(\left(V_{i}^{T}\right)_{i \in N}\right)$ but $x \notin V^{T}$. Then, $\left\{i \in N \mid x \in V_{i}^{T}\right\} \in \mathcal{W}_{x}$. If $x \in V_{i}^{T}$ there exists $1 \leq t_{i} \leq T$ such that $x \in \bar{V}_{i}^{t_{i}}$ because $V_{i}^{T}=\cup_{t=1}^{T} \bar{V}_{i}^{t}$. By property (3.1), $x \in \bar{V}_{i}^{T}$ because $x \notin V^{T}, V^{T}=\cup_{t=1}^{T} \bar{V}^{t}$, and $x \in \bar{V}_{i}^{t_{i}}$. Then, $\left\{i \in N \mid x \in \bar{V}_{i}^{T}\right\} \in \mathcal{W}_{x}$ and hence, $x \in \bar{V}^{T} \subset V^{T}$, which is a contradiction.

We now prove that $v\left(\left(V_{i}^{T}\right)_{i \in N}\right)=v\left(\left(Z_{i}\right)_{i \in N}\right)$. We know that $V_{i}^{T} \subset Z_{i}$ for all $i \in N$. Then, $v\left(\left(V_{i}^{T}\right)_{i \in N}\right) \subset v\left(\left(Z_{i}\right)_{i \in N}\right)$. Suppose that $x \in v\left(\left(Z_{i}\right)_{i \in N}\right)$ but $x \notin v\left(\left(V_{i}^{T}\right)_{i \in N}\right)$. Then, $x \in H_{i}$ for some $i \in N$ and hence, by definition of $H_{i}$, $x \in V^{T} \subset v\left(\left(V_{i}^{T}\right)_{i \in N}\right)$, which is a contradiction.

\section{Appendix D. Proof of Theorem 1}

The proof of Theorem 1 follows from the following three Lemmata, which assume that $R \in \mathcal{D}$ and $v$ is a voting by committees without vetoers.

Lemma 2 Let $i \in N$ and $X \subset K$. Then, 
a) to vote for $X \cap G\left(R_{i}\right)$ is at least as good as to vote for $X$;

b) if there exists $x \in X \cap B\left(R_{i}\right)$ such that $i$ is not a dummy for $x$ then, to vote for $X$ is dominated by to vote for $X \cap G\left(R_{i}\right)$.

Proof Assume that $X^{\prime}=X \cap G\left(R_{i}\right)$.

a) We prove that given $S_{i}^{\prime}=X^{\prime}, S_{i}=X, S_{j} \subset K$ for all $j \in N \backslash\{i\}$, then, $u_{i}\left(S_{i}^{\prime}, S_{-i}\right) \geq u_{i}\left(S_{i}, S_{-i}\right)$. Take $T^{\prime}=v\left(S_{i}^{\prime}, S_{-i}\right)$ and $T=v\left(S_{i}, S_{-i}\right)$. By definition,

$$
u_{i}\left(S_{i}^{\prime}, S_{-i}\right)=\left\{\begin{array}{lc}
\sum_{j \in N \backslash E A\left(T^{\prime}\right)} u_{i}(j)+\sum_{j \in T^{\prime}} u_{i}(j) & \text { if } i \notin E A\left(T^{\prime}\right) \\
0 & \text { otherwise. }
\end{array}\right.
$$

Since $X^{\prime} \subset X, T^{\prime} \subset T$. By property (2.1), $E A\left(T^{\prime}\right) \subset E A(T)$. Then, because preferences are monotonic,

$$
\sum_{j \in N \backslash E A\left(T^{\prime}\right)} u_{i}(j) \geq \sum_{j \in N \backslash E A(T)} u_{i}(j) .
$$

Since $X^{\prime}=X \cap G\left(R_{i}\right), \sum_{j \in T^{\prime}} u_{i}(j) \geq \sum_{j \in T} u_{i}(j)$. We consider three cases:

- $i \in E A\left(T^{\prime}\right) \subset E A(T)$. Then,

$$
u_{i}\left(S_{i}^{\prime}, S_{-i}\right)=u_{i}\left(S_{i}, S_{-i}\right)=0 .
$$

- $i \notin E A\left(T^{\prime}\right)$ but $i \in E A(T)$. Then,

$$
u_{i}\left(S_{i}^{\prime}, S_{-i}\right)=\sum_{j \in N \backslash E A\left(T^{\prime}\right)} u_{i}(j)+\sum_{j \in T^{\prime}} u_{i}(j) \geq 0=u_{i}\left(S_{i}, S_{-i}\right) .
$$

- $i \notin E A\left(T^{\prime}\right)$ and $i \notin E A(T)$. Then,

$$
\begin{aligned}
u_{i}\left(S_{i}^{\prime}, S_{-i}\right) & =\sum_{j \in N \backslash E A\left(T^{\prime}\right)} u_{i}(j)+\sum_{j \in T^{\prime}} u_{i}(j) \\
& \geq \sum_{j \in N \backslash E A(T)} u_{i}(j)+\sum_{j \in T} u_{i}(j) \\
& =u_{i}\left(S_{i}, S_{-i}\right) .
\end{aligned}
$$

b) Take $X^{*}=\left\{x \in X \cap B\left(R_{i}\right) \mid i\right.$ is not a dummy for $\left.x\right\}$. Assume $X^{*} \neq \emptyset$. For any $x \in X^{*}$, let $W_{x} \in \mathcal{W}_{x}^{m}$ be such that $i \in W_{x}$. We now prove that there exists $S_{-i}=\left(S_{j}\right)_{j \in N \backslash\{i\}}$ satisfying $u_{i}\left(S_{i}^{\prime}, S_{-i}\right)>u_{i}\left(S_{i}, S_{-i}\right)$. For each $j \in N \backslash\{i\}$ define $S_{j}=X^{\prime} \cup\left\{x \in X^{*} \mid j \in W_{x}\right\}$. Then, $v\left(S_{i}^{\prime}, S_{-i}\right)=X^{\prime}$ and $v\left(S_{i}, S_{-i}\right)=X^{\prime} \cup X^{*}=Y$. Then,

$$
\sum_{j \in X^{\prime}} u_{i}(j)>\sum_{j \in Y} u_{i}(j) .
$$


By property (2.1), $E A\left(X^{\prime}\right) \subset E A(Y)$ and hence

$$
\sum_{j \in N \backslash E A\left(X^{\prime}\right)} u_{i}(j) \geq \sum_{j \in N \backslash E A(Y)} u_{i}(j) .
$$

Then,

$$
\sum_{j \in N \backslash E A\left(X^{\prime}\right)} u_{i}(j)+\sum_{j \in X^{\prime}} u_{i}(j)>\sum_{j \in N \backslash E A(Y)} u_{i}(j)+\sum_{j \in Y} u_{i}(j) .
$$

Since $X^{\prime} \subset G\left(R_{i}\right)$ we conclude that $i \notin E A\left(X^{\prime}\right)$. Then,

$$
u_{i}\left(S_{i}^{\prime}, S_{-i}\right)=\sum_{j \in N \backslash E A\left(X^{\prime}\right)} u_{i}(j)+\sum_{j \in X^{\prime}} u_{i}(j)>0 .
$$

We consider two cases.

- $i \in E A(Y)$. Then, $u_{i}\left(S_{i}^{\prime}, S_{-i}\right)>u_{i}\left(S_{i}, S_{-i}\right)$ because $u_{i}\left(S_{i}, S_{-i}\right)=0$.

- $i \notin E A(Y)$. Then, $u_{i}\left(S_{i}^{\prime}, S_{-i}\right)>u_{i}\left(S_{i}, S_{-i}\right)$ because

$$
u_{i}\left(S_{i}, S_{-i}\right)=\sum_{j \in N \backslash E A(Y)} u_{i}(j)+\sum_{j \in Y} u_{i}(j) .
$$

Lemma 3 For each $i \in N$, the strategy $Z_{i}$ is undominated.

Proof Assume that $Z_{i}$ is dominated by $V_{i}^{\prime}$ and $Z_{i} \neq V_{i}^{\prime}$. Then, for each $S=$ $\left(S_{1}, \ldots, S_{n}\right) \in\left(2^{K}\right)^{N}, u_{i}\left(V_{i}^{\prime}, S_{-i}\right) \geq u_{i}\left(Z_{i}, S_{-i}\right)$. By Remark 3, $i \notin E A\left(Z_{i}\right)$. Since $Z_{i}$ is dominated by $V_{i}^{\prime}$ we conclude that $i \notin E A\left(V_{i}^{\prime}\right)$. By Lemma 2 a), we can assume that $V_{i}^{\prime} \cap B\left(R_{i}\right)=\emptyset$. We will get a contradiction by proving that $V_{i}^{\prime}=Z_{i}$. We first prove that $Z_{i} \subset V_{i}^{\prime}$ and later that $V_{i}^{\prime} \cap\left(K \backslash Z_{i}\right)=\emptyset$.

1. $Z_{i} \subset V_{i}^{\prime}$. We can assume, without loss of generality, that if $i$ is a dummy for $x$ and $x \in Z_{i}$ then $x \in V_{i}^{\prime}$. If not, take

$$
V_{i}^{\prime \prime}=V_{i}^{\prime} \cup\left\{x \in Z_{i} \text { such that } i \text { is a dummy for } x\right\}
$$

and proceed with $V_{i}^{\prime \prime}$ instead of $V_{i}^{\prime}$. Notice that $V_{i}^{\prime \prime}$ and $V_{i}^{\prime}$ are payoff equivalent for $i$.

We first prove that $V_{i}^{T} \subset V_{i}^{\prime}$ by induction on $t$. We start by proving that $V_{i}^{1} \subset V_{i}^{\prime}$. Suppose not. Then, $Q=V_{i}^{1} \backslash V_{i}^{\prime} \neq \emptyset$. Given $x \in Q$ let $W_{x} \in \mathcal{W}_{x}^{m}$ be such that $i \in W_{x}$. We know that $W_{x}$ exists because $i$ is not a dummy for $x$. For each $j \in N \backslash\{i\}$ define $S_{j}=V_{i}^{\prime} \cup\left\{x \in Q \mid j \in W_{x}\right\}$. Of course, 
$v\left(V_{i}^{\prime}, S_{-i}\right)=V_{i}^{\prime}$. Moreover, $V_{i}^{\prime} \subset v\left(Z_{i}, S_{-i}\right)$ because $v$ has no vetoers. Since $Q \subset V_{i}^{1} \subset Z_{i}$ it is easy to conclude that $v\left(Z_{i}, S_{-i}\right)=V_{i}^{\prime} \cup Q$. Since $i \notin E A\left(Z_{i}\right)$ and $i \notin E A\left(V_{i}^{\prime}\right)$ we conclude, by property (2.1), that $i \notin E A\left(V_{i}^{\prime} \cup Z_{i}\right)$ and $i \notin E A\left(V_{i}^{\prime} \cup Q\right)$. Then,

$$
u_{i}\left(Z_{i}, S_{-i}\right)-u_{i}\left(V_{i}^{\prime}, S_{-i}\right)=\sum_{j \in f\left(V_{i}^{\prime} \cup Q\right)} u_{i}(j)-\sum_{j \in f\left(V_{i}^{\prime}\right)} u_{i}(j) .
$$

By definition of $\bar{V}_{i}^{1}\left(=V_{i}^{1}\right)$ and since $\emptyset \neq Q \subset G\left(R_{i}\right)$,

$$
\sum_{j \in f\left(V_{i}^{1}\right)} u_{i}(j)-\sum_{j \in f\left(V_{i}^{1} \backslash Q\right)} u_{i}(j)>0 .
$$

Applying property (2.3) in Proposition 2 when defining $A, B$, and $C$ as $V_{i}^{1} \backslash Q=$ $V_{i}^{1} \cap V_{i}^{\prime}, V_{i}^{\prime}$, and $Q$, respectively, we obtain that

$$
u_{i}\left(Z_{i}, S_{-i}\right)-u_{i}\left(V_{i}^{\prime}, S_{-i}\right) \geq \sum_{j \in f\left(V_{i}^{1}\right)} u_{i}(j)-\sum_{j \in f\left(V_{i}^{1} \backslash Q\right)} u_{i}(j)>0,
$$

which contradicts that $Z_{i}$ is dominated by $V_{i}^{\prime}$. Then, $V_{i}^{1} \subset V_{i}^{\prime}$.

Induction hypothesis: Assume that $V_{i}^{t} \subset V_{i}^{\prime}$.

We now prove that $V_{i}^{t+1} \subset V_{i}^{\prime}$. We assume that $i \notin E A\left(V^{t}\right)$, otherwise the result is trivial because $V_{i}^{T}=V_{i}^{t}$. Since $V_{i}^{t+1}=V_{i}^{t} \cup \bar{V}_{i}^{t+1}$ it is enough to prove that $\bar{V}_{i}^{t+1} \subset V_{i}^{\prime}$. Suppose not. Then, $Q=\bar{V}_{i}^{t+1} \backslash V_{i}^{\prime} \neq \emptyset$. Given $x \in Q$ let $W_{x} \in \mathcal{W}_{x}^{m}$ be such that $i \in W_{x}$. We know that $W_{x}$ exists because $i$ is not a dummy for $x$. For each $j \in N \backslash\{i\}$ define $S_{j}=V_{i}^{\prime} \cup V^{t} \cup\left\{x \in Q \mid j \in W_{x}\right\}$. Since $v$ has no vetoers, $V_{i}^{\prime} \cup V^{t} \subset v\left(Z_{i}, S_{-i}\right)$ and $V_{i}^{\prime} \cup V^{t} \subset v\left(V_{i}^{\prime}, S_{-i}\right)$. Now it is easy to conclude that $v\left(V_{i}^{\prime}, S_{-i}\right)=V_{i}^{\prime} \cup V^{t}$ and $v\left(Z_{i}, S_{-i}\right)=V_{i}^{\prime} \cup V^{t} \cup Q$. Then,

$$
u_{i}\left(Z_{i}, S_{-i}\right)-u_{i}\left(V_{i}^{\prime}, S_{-i}\right)=\sum_{j \in f\left(V^{t} \cup V_{i}^{\prime} \cup Q\right)} u_{i}(j)-\sum_{j \in f\left(V^{t} \cup V_{i}^{\prime}\right)} u_{i}(j) .
$$

By definition of $\bar{V}_{i}^{t+1}$,

$$
\sum_{j \in f\left(V^{t} \cup \bar{V}_{i}^{t+1}\right)} u_{i}(j)-\sum_{j \in f\left(V^{t} \cup\left(\bar{V}_{i}^{t+1} \backslash Q\right)\right)} u_{i}(j)>0 .
$$

Applying property (2.3) in Proposition 2 when defining $A, B$, and $C$ as $\left(V^{t} \cup \bar{V}_{i}^{t+1}\right) \backslash Q=V^{t} \cup\left(\bar{V}_{i}^{t+1} \backslash Q\right), V^{t} \cup V_{i}^{\prime}$, and $Q$, respectively, we obtain that

$$
u_{i}\left(Z_{i}, S_{-i}\right)-u_{i}\left(V_{i}^{\prime}, S_{-i}\right) \geq \sum_{j \in f\left(V^{t} \cup \bar{V}_{i}^{t+1}\right)} u_{i}(j)-\sum_{j \in f\left(V^{t} \cup\left(\bar{V}_{i}^{t+1} \backslash Q\right)\right)} u_{i}(j)>0
$$


which contradicts that $Z_{i}$ is dominated by $V_{i}^{\prime}$. Then, $\bar{V}_{i}^{t+1} \subset V_{i}^{\prime}$ and hence, $V_{i}^{t+1} \subset V_{i}^{\prime}$.

We have proved that $V_{i}^{T} \subset V_{i}^{\prime}$. We now prove that $H_{i} \subset V_{i}^{\prime}$. Suppose not, then $Q=H_{i} \backslash V_{i}^{\prime} \neq \emptyset$. Given $x \in Q$ let $W_{x} \in \mathcal{W}_{x}^{m}$ be such that $i \in W_{x}$. We know that $W_{x}$ exists because $i$ is not a dummy for $x$. For each $j \in N \backslash\{i\}$ define $S_{j}=V_{i}^{\prime} \cup\left\{x \in Q \mid j \in W_{x}\right\}$. Using arguments similar to those already used before we conclude that $v\left(V_{i}^{\prime}, S_{-i}\right)=V_{i}^{\prime}$ and $v\left(Z_{i}, S_{-i}\right)=V_{i}^{\prime} \cup Q$. Then,

$$
u_{i}\left(Z_{i}, S_{-i}\right)-u_{i}\left(V_{i}^{\prime}, S_{-i}\right)=\sum_{j \in f\left(V_{i}^{\prime} \cup Q\right)} u_{i}(j)-\sum_{j \in f\left(V_{i}^{\prime}\right)} u_{i}(j) .
$$

By definition of $H_{i}$,

$$
\sum_{j \in f\left(V_{i}^{T} \cup H_{i}\right)} u_{i}(j)-\sum_{j \in f\left(V_{i}^{T} \cup\left(H_{i} \backslash Q\right)\right)} u_{i}(j)>0 .
$$

Applying property (2.3) in Proposition 2 when defining $A, B$, and $C$ as $\left(V_{i}^{T} \cup H_{i}\right) \backslash Q=V_{i}^{T} \cup\left(H_{i} \backslash Q\right), V_{i}^{\prime}$, and $Q$, respectively, we obtain that

$$
u_{i}\left(Z_{i}, S_{-i}\right)-u_{i}\left(V_{i}^{\prime}, S_{-i}\right) \geq \sum_{j \in f\left(V_{i}^{T} \cup H_{i}\right)} u_{i}(j)-\sum_{j \in f\left(V_{i}^{T} \cup\left(H_{i} \backslash Q\right)\right)} u_{i}(j)>0,
$$

which contradicts that $Z_{i}$ is dominated by $V_{i}^{\prime}$. Then, $H_{i} \subset V_{i}^{\prime}$. Since $Z_{i}=$ $V_{i}^{T} \cup H_{i}$ we conclude that $Z_{i} \subset V_{i}^{\prime}$.

2. $V_{i}^{\prime} \cap\left(K \backslash Z_{i}\right)=\emptyset$. Suppose not. We already know that $V_{i}^{\prime} \cap B\left(R_{i}\right)=\emptyset$. We can assume without loss of generality that if $i$ is a dummy for $x$ and $x \notin Z_{i}$ then $x \notin V_{i}^{\prime}$. If not, take

$$
V_{i}^{\prime \prime}=V_{i}^{\prime} \backslash\left\{x \in V_{i}^{\prime} \text { such that } i \text { is a dummy for } x\right\}
$$

and proceed with $V_{i}^{\prime \prime}$ instead of $V_{i}^{\prime}$. Notice that $V_{i}^{\prime \prime}$ and $V_{i}^{\prime}$ are payoff equivalent for $i$. We consider two cases:

- $i \notin E A\left(V^{T}\right)$.

- We first prove that $\left(V_{i}^{\prime} \backslash Z_{i}\right) \cap\left(G\left(R_{i}\right) \backslash A_{i}\right)=\emptyset$. Suppose not. Then, $Q=\left(V_{i}^{\prime} \backslash Z_{i}\right) \cap\left(G\left(R_{i}\right) \backslash A_{i}\right) \neq \emptyset$. Given $x \in Q$ let $W_{x} \in \mathcal{W}_{x}^{m}$ be such that $i \in W_{x}$. We know that $W_{x}$ exists because $i$ is not a dummy for $x$. By the process defining $Z$ (step $T$ ) we know that for any subset $Q^{\prime} \subset K$ if $V^{T-1} \cap Q^{\prime}=\emptyset$ and $Q^{\prime} \neq \bar{V}_{i}^{T}$,

$$
\sum_{j \in f\left(V^{T-1} \cup \bar{V}_{i}^{T}\right)} u_{i}(j)>\sum_{j \in f\left(V^{T-1} \cup Q^{\prime}\right)} u_{i}(j) .
$$


For each $j \in N \backslash\{i\}$ define $S_{j}=V^{T-1} \cup \bar{V}_{i}^{T} \cup\left\{x \in Q \mid j \in W_{x}\right\}$. Using arguments similar to those already used before we conclude that $V^{T-1} \cup \bar{V}_{i}^{T} \cup Q \subset v\left(V_{i}^{\prime}, S_{-i}\right)$ and $v\left(Z_{i}, S_{-i}\right)=V^{T-1} \cup \bar{V}_{i}^{T}$. Take $Q^{\prime}=v\left(V_{i}^{\prime}, S_{-i}\right) \backslash V^{T-1}$, then

$$
u_{i}\left(Z_{i}, S_{-i}\right)=\sum_{j \in f\left(V^{T-1} \cup \bar{V}_{i}^{T}\right)} u_{i}(j)
$$

and

$$
u_{i}\left(V_{i}^{\prime}, S_{-i}\right)=\sum_{j \in f\left(V^{T-1} \cup Q^{\prime}\right)} u_{i}(j) .
$$

Since $V^{T-1} \cap Q^{\prime}=\emptyset$ and $Q^{\prime} \supset \bar{V}_{i}^{T} \cup Q \supsetneq \bar{V}_{i}^{T}, u_{i}\left(Z_{i}, S_{-i}\right)>$ $u_{i}\left(V_{i}^{\prime}, S_{-i}\right)$, which contradicts that $Z_{i}$ is dominated by $V_{i}^{\prime}$.

- We now prove that $\left(V_{i}^{\prime} \backslash Z_{i}\right) \cap A_{i}=\emptyset$. Suppose not. Then, $Q=$ $\left(V_{i}^{\prime} \backslash Z_{i}\right) \cap A_{i} \neq \emptyset$. Given $x \in Q$ let $W_{x} \in \mathcal{W}_{x}^{m}$ be such that $i \in W_{x}$. We know that $W_{x}$ exists because $i$ is not a dummy for $x$. By definition of $H_{i}$ we know that for all $Q^{\prime} \subset A_{i}, Q^{\prime} \neq H_{i}$,

$$
\sum_{j \in f\left(V_{i}^{T} \cup H_{i}\right)} u_{i}(j)>\sum_{j \in f\left(V_{i}^{T} \cup Q^{\prime}\right)} u_{i}(j) .
$$

For each $j \in N \backslash\{i\}$ define $S_{j}=V_{i}^{T} \cup H_{i} \cup\left\{x \in Q \mid j \in W_{x}\right\}$. Using arguments similar to those already used before we conclude that $V_{i}^{T} \cup$ $H_{i} \cup Q \subset v\left(V_{i}^{\prime}, S_{-i}\right)$ and $v\left(Z_{i}, S_{-i}\right)=V_{i}^{T} \cup H_{i}$. Since $\left(V_{i}^{\prime} \backslash Z_{i}\right) \cap$ $\left(G\left(R_{i}\right) \backslash A_{i}\right)=\emptyset$ we conclude that $v\left(V_{i}^{\prime}, S_{-i}\right)=V_{i}^{T} \cup H_{i} \cup Q$. Take $Q^{\prime}=H_{i} \cup Q$, then

$$
u_{i}\left(Z_{i}, S_{-i}\right)=\sum_{j \in f\left(V_{i}^{T} \cup H_{i}\right)} u_{i}(j)
$$

and

$$
u_{i}\left(V_{i}^{\prime}, S_{-i}\right)=\sum_{j \in f\left(V_{i}^{T} \cup Q^{\prime}\right)} u_{i}(j) .
$$

Since $Q^{\prime} \subset A_{i}$ and $Q^{\prime} \neq H_{i}(Q \neq \emptyset)$ we conclude that $u_{i}\left(Z_{i}, S_{-i}\right)>$ $u_{i}\left(V_{i}^{\prime}, S_{-i}\right)$, which contradicts that $Z_{i}$ is dominated by $V_{i}^{\prime}$.

- $i \in E A\left(V^{T}\right)$. Then, there exists $t<T$ such that $i \notin E A\left(V^{t-1}\right), i \in$ $E A\left(V^{t}\right)$, and $Z_{i}=V_{i}^{t} \cup H_{i}$. Using the same arguments that in the case $i \notin E A\left(V^{T}\right)$ we obtain a contradiction. 
Lemma $4\left(Z_{1}, \ldots, Z_{n}\right)$ is a Nash equilibrium of $\Gamma(v, R)$.

Proof We prove that for all $i \in N, u_{i}\left(Z_{i}, Z_{-i}\right) \geq u_{i}\left(V_{i}^{\prime}, Z_{-i}\right)$ for all $V_{i}^{\prime} \in 2^{K}$.

Assume that $i \in E A\left(V^{T}\right)$. By property (2.1) there exists $x \in V^{T}$ such that $i \in E A(x)$. Because of the process defining $Z$ there exists $t \leq T$ such that $\left\{j \in N \backslash\{i\} \mid x \in \bar{V}_{j}^{t}\right\} \in \mathcal{W}_{x}$ and hence $\left\{j \in N \backslash\{i\} \mid x \in Z_{j}\right\} \in \mathcal{W}_{x}$. Then, $x \in$ $v\left(V_{i}^{\prime}, Z_{-i}\right)$, which means that $i \in E A\left(V_{i}^{\prime}, Z_{-i}\right)$. Therefore, $u_{i}(Z)=u_{i}\left(V_{i}^{\prime}, Z_{-i}\right)$.

Assume now that $i \notin E A\left(V^{T}\right)$. We prove it by contradiction. Suppose that $u_{i}\left(V_{i}^{\prime}, Z_{-i}\right)>u_{i}\left(V_{i}, Z_{-i}\right)$. By property $(3.2), v\left(Z_{i}, Z_{-i}\right)=V^{T}$ and hence, $u_{i}\left(Z_{i}, Z_{-i}\right)=$ $\sum_{j \in f\left(V^{T}\right)} u_{i}(j)$. Since $u_{i}\left(V_{i}^{\prime}, Z_{-i}\right)>u_{i}\left(Z_{i}, Z_{-i}\right)$ and $i \notin E A\left(V^{T}\right), u_{i}\left(V_{i}^{\prime}, Z_{-i}\right)=$ $\sum_{j \in f\left(V^{\prime}\right)} u_{i}(j)$, where $V^{\prime}=v\left(V_{i}^{\prime}, Z_{-i}\right)$. We assume, without loss of generality, that $V_{i}^{\prime} \subset\left(Z_{i} \cup V^{\prime}\right)$. If not, take $V_{i}^{\prime \prime}=V_{i}^{\prime} \cap\left(Z_{i} \cup V^{\prime}\right)$ and proceed with $V_{i}^{\prime \prime}$ instead of $V_{i}^{\prime}$ because $v\left(V_{i}^{\prime \prime}, Z_{-i}\right)=v\left(V_{i}^{\prime}, Z_{-i}\right)$. We proceed in two steps.

1. We prove that if $Q=V_{i}^{\prime} \cap\left(V^{\prime} \backslash V^{T}\right) \neq \emptyset$ then $V_{i}^{*}=V_{i}^{\prime} \cap Z_{i}$ satisfies

$$
\sum_{j \in f\left(V^{*}\right)} u_{i}(j)>\sum_{j \in f\left(V^{T}\right)} u_{i}(j)
$$

where $V^{*}=v\left(V_{i}^{*}, Z_{-i}\right)$. Notice that $V^{\prime}=V^{*} \cup Q$, and $V^{*} \subset V^{T}$. Since $V^{T}=V^{T-1}, Q \subset V^{\prime}$, and $Q \cap V^{T}=\emptyset$. Because of the definition of Stage $T$ of the process, $Q \cap \bar{V}_{i}^{T}=\emptyset$. Then, by definition of $\bar{V}_{i}^{T}$,

$$
\sum_{j \in f\left(V^{T} \cup \bar{V}_{i}^{T}\right)} u_{i}(j)>\sum_{j \in f\left(V^{T} \cup \bar{V}_{i}^{T} \cup Q\right)} u_{i}(j) .
$$

Applying property (2.3) in Proposition 2 when defining $A, B$, and $C$ as $V^{T}$, $V^{T} \cup \bar{V}_{i}^{T}$, and $Q$, respectively, we obtain that

$$
\sum_{j \in f\left(V^{T} \cup \bar{V}_{i}^{T} \cup Q\right)} u_{i}(j)-\sum_{j \in f\left(V^{T} \cup \bar{V}_{i}^{T}\right)} u_{i}(j) \geq \sum_{j \in f\left(V^{T} \cup Q\right)} u_{i}(j)-\sum_{j \in f\left(V^{T}\right)} u_{i}(j) .
$$

Then,

$$
\sum_{j \in f\left(V^{T}\right)} u_{i}(j)>\sum_{j \in f\left(V^{T} \cup Q\right)} u_{i}(j) .
$$

We know that $V^{*} \subset V^{T}$. If $V^{*}=V^{T}$ we get a contradiction because $V^{\prime}=V^{*} \cup$ $Q=V^{T} \cup Q$. Assume that $V^{*} \neq V^{T}$. Applying property (2.3) in Proposition 2 when defining $A, B$, and $C$ as $V^{*}, V^{T}$, and $Q$, respectively, we obtain that

$$
\sum_{j \in f\left(V^{T} \cup Q\right)} u_{i}(j)-\sum_{j \in f\left(V^{T}\right)} u_{i}(j) \geq \sum_{j \in f\left(V^{\prime}\right)} u_{i}(j)-\sum_{j \in f\left(V^{*}\right)} u_{i}(j) .
$$


Then,

$$
\sum_{j \in f\left(V^{*}\right)} u_{i}(j)>\sum_{j \in f\left(V^{\prime}\right)} u_{i}(j)>\sum_{j \in f\left(V^{T}\right)} u_{i}(j) .
$$

As a consequence of this part we can assume, without loss of generality, that $V_{i}^{\prime} \subset Z_{i}$. Then, $V^{\prime} \subset V^{T}$.

2. For each $t=1, \ldots, T$ we define $S^{t}=\bar{V}^{t} \cap\left(K \backslash V^{\prime}\right)$. Assume that $x \in S^{t}$. According with $Z_{i}$, candidate $x$ is elected in stage $t$ of the process. According with $V_{i}^{\prime}, x$ is not elected. Then, member $i$ votes for $x$ in Stage $t\left(x \in \bar{V}_{i}^{t}\right)$.

Notice that $V^{\prime}=\bigcup_{t=1}^{T}\left(\bar{V}^{t} \backslash S^{t}\right)$. We will get a contradiction by proving that

$$
\sum_{j \in f\left(V^{T}\right)} u_{i}(j) \geq \sum_{j \in f\left(V^{\prime}\right)} u_{i}(j)
$$

For all $t=1, \ldots, T+1$ we define

$$
R^{t}=V^{t-1} \cup\left(\cup_{a=t}^{T}\left(\bar{V}^{a} \backslash S^{a}\right)\right) .
$$

Observe that $R^{1}=V^{\prime}, R^{T+1}=V^{T}$ and $R^{t+1}=R^{t} \cup S^{t}$ for all $t=1, \ldots, T-1$ (by convenience we take $V^{0}=\emptyset$ ). We proceed by induction. We first prove that $R^{T}$ satisfies

$$
\sum_{j \in f\left(R^{T+1}\right)} u_{i}(j) \geq \sum_{j \in f\left(R^{T}\right)} u_{i}(j)
$$

Notice that $R^{T}=V^{T-1} \cup\left(\bar{V}^{T} \backslash S^{T}\right)=V^{T}$ because $\bar{V}^{T}=\emptyset$. Then, the result holds trivially. Assume now that for all $t=t^{*}+1, \ldots, T$,

$$
\sum_{j \in f\left(R^{t+1}\right)} u_{i}(j) \geq \sum_{j \in f\left(R^{t}\right)} u_{i}(j) .
$$

We now prove that

$$
\sum_{j \in f\left(R^{t^{*}+1}\right)} u_{i}(j)-\sum_{j \in f\left(R^{t^{*}}\right)} u_{i}(j) \geq 0
$$

If $S^{t^{*}}=\emptyset$ the result holds trivially because $R^{t^{*}+1}=R^{t^{*}}$. Assume that $S^{t^{*}} \neq \emptyset$. By definition of $\bar{V}_{i}^{t^{*}}$ we know that

$$
\sum_{j \in f\left(V^{t^{*}-1} \cup \bar{V}_{i}^{t^{*}}\right)} u_{i}(j)-\sum_{j \in f\left(V^{t^{*}-1} \cup\left(\bar{V}_{i}^{t^{*}} \backslash S^{t^{*}}\right)\right)} u_{i}(j)>0 .
$$

Applying property (2.3) in Proposition 2 when defining $A, B$, and $C$ as $V^{t^{*}-1} \cup$ $\left(\bar{V}^{t^{*}} \backslash S^{t^{*}}\right), R^{t^{*}}$, and $S^{t^{*}}$, respectively, we obtain that

$$
\sum_{j \in f\left(R^{t^{*}+1}\right)} u_{i}(j)-\sum_{j \in f\left(R^{t^{*}}\right)} u_{i}(j) \geq \sum_{j \in f\left(V^{t^{*}-1} \cup \bar{V}_{i}^{t^{*}}\right)} u_{i}(j)-\sum_{j \in\left(V^{t^{*}-1} \cup\left(\bar{V}_{i}^{t^{*}} \backslash S^{t^{*}}\right)\right)} u_{i}(j) \geq 0 .
$$


Then, $\sum_{j \in f\left(V^{T}\right)} u_{i}(j)=\sum_{j \in f\left(R^{T+1}\right)} u_{i}(j) \geq \ldots \geq \sum_{j \in f\left(R^{1}\right)} u_{i}(j)=\sum_{j \in f\left(V^{\prime}\right)} u_{i}(j)$, which is the desired contradiction.

\section{References}

Barberà, S., Maschler, M., and Shalev, J., 2001. Voting for voters: a model of electoral evolution. Games and Economic Behavior 37, 40-78.

Barberà, S., Sonnenschein, H., and Zhou, L., 1991. Voting by committees. Econometrica 59, 595-609.

Berga, D., Bergantiños, G., Massó, J., and Neme, A., 2004. Stability and voting by committees with exit. Social Choice and Welfare 23, 229-247.

Berga, D., Bergantiños, G., Massó, J., and Neme, A., 2006. On exiting after voting. International Journal of Game Theory 34, 33-54.

Dutta, B., Jackson, M., and Le Breton, M., 2001. Strategic candidacy and voting procedures. Econometrica 69, 1013-1037.

Ehlers, L. and Weymark, J., 2003. Candidate stability and nonbinary social choice. Economic Theory 22, 233-243.

Eraslan, H. and McLennan, A., 2004. Strategic candidacy for multivalued voting procedures. Journal of Economic Theory 117, 29-54.

Granot, D., Maschler, M., and Shalev, J., 2002. Voting for voters: the unanimity case. International Journal of Game Theory 31, 155-202.

Rodríguez-Álvarez, C. 2006. Candidate stability and voting correspondences. Social Choice and Welfare 27, 545-570. 